\title{
Efekt bronchodylatacyjny kombinacji salbutamolu i bromku ipratropium z nebulizatora siateczkowego u dzieci chorych na astmę (doniesienie wstępne)
} The bronchodilatory effect of the salbutamol and ipratropium bromide combination from mesh nebulizer in asthmatic children (preliminary report)

Andrzej Emeryk', Iwona Czerwińska-Pawluk², Ewa Markut-Miotła', Kamil Janeczek ${ }^{1}$ Klinika Chorób Płuc i Reumatologii Dziecięcej, Uniwersytet Medyczny w Lublinie Kierownik: prof. dr hab. n. med. Andrzej Emeryk

${ }_{2}^{2}$ Pracownia Badań Czynnościowych Układu Oddechowego - Uniwersytecki Szpital Dziecięcy w Lublinie Kierownik: prof. dr hab. n. med. Andrzej Emeryk

\section{Streszczenie:}

Porównano bronchodylatacyjną odpowiedź oskrzeli po podaniu kombinacji salbutamolu z bromkiem ipratropium vs sam salbutamol inhalowanych z nebulizatora siateczkowego u dzieci w wieku 6-11 lat z cechami klinicznymi i spirometrycznymi zaostrzenia astmy. Wykazano porównywalny efekt bronchodylatacyjny obu terapii w 15 . min po podaniu leku.

\section{Abstract:}

Bronchodilatory response to the combination of salbutamol and ipratropium bromide vs salbutamol alone inhaled from the mesh nebulizer in children aged 6-11 years with clinical and spirometric features of asthma exacerbation was compared. A comparable bronchodilatory effect of both treatments was demonstrated in $15^{\text {th }}$ minute after drug administration.

Słowa kluczowe: astma, dzieci, inhalator siateczkowy, salbutamol, bromek ipratropium

Key words: asthma, children, mesh nebulizers, salbutamol, ipratropium bromide

Wstęp

W terapii napadu astmy lub jej zaostrzenia u dzieci przed 12. r.ż. od wielu lat standardem postępowania farmakologicznego i najważniejszym lekiem jest $\beta_{2}$-mimetyk krótko działający (SABA) na żądanie (PRN) w formie inhalacyjnej [1-3]. U dzieci starszych i dorosłych preferowanym postępowaniem ratunkowym jest doraźne stosowanie niskiej dawki budezoni$\mathrm{du} \mathrm{z}$ formoterolem, a alternatywnym SABA PRN lub
SABA w kombinacji z glikokortykosteroidem wziewnym (GKSw) [1]. SABA w inhalacji jest także stosowany jako złoty standard w ocenie bronchodylatacyjnej odpowiedzi oskrzeli (bronchodilator responsiveness testing) u dzieci i dorosłych, ważnym narzędziem diagnostycznym w astmie i POChP $[1,4]$. Dysponujemy w kraju dwoma lekami z grupy SABA w inhalacji: salbutamolem (S) i fenoterolem (F). Różnią się one istotnie kilkoma elementami. Wskaźnik pobudzania 
receptorów $\beta_{2} / \beta_{1}$ (wskaźnik selektywności) jest ponad 10 razy większy dla $\mathrm{S}$ niż F. Biorąc pod uwagę zbliżone możliwości pobudzania receptorów $\beta_{2}$ przez oba leki $(0,55 \mathrm{~S}$ vs $0,60 \mathrm{~F})$, oznacza to większą selektywność stymulacji receptorów $\beta_{2}$ przez $\mathrm{S}$ vs $\mathrm{F}$ i porównywalne działanie bronchodylatacyjne obu leków [5]. Badania udowodniły większą efektywność kliniczną i bezpieczeństwo inhalacji $\mathrm{S}$ vs $\mathrm{F}$ w różnych grupach chorych na astmę, w tym także u dzieci [6-8]. Większe bezpieczeństwo $\mathrm{S}$ niż $\mathrm{F}$ wynika m.in. z tego, iż $\mathrm{S}$ ma wyraźniejsze cechy częściowego agonisty $\beta_{2}$-receptorów niż F. Skutkuje to mniejszym ryzykiem zgonu chorych na astmę stosujących $\mathrm{S}$ vs $\mathrm{F}[8,9]$.

Należy pamiętać, że niekorzystne cechy $\mathrm{F}$ nasilają się jeszcze w warunkach hipoksemii, a taka sytuacja zachodzi w ciężkim, przedłużającym się epizodzie obturacji oskrzeli [10]. W zaleceniach i rekomendacjach dotyczących postępowania w zaostrzeniach astmy uwzględnia się także bromek ipratropium (BI) $[1,11]$. Ten krótko działający lek antycholinergiczny (SAMA) powinien być dodany do SABA lub podawany w połączeniu $\mathrm{z}$ SABA w zaostrzeniu umiarkowanym/ciężkim przy braku odpowiedzi na właściwe dawkowanie SABA [1, 11, 12]. SAMA cechuje wolniejszy początek działania i słabszy efekt rozszerzający oskrzela vs SABA. SAMA zmniejszają specyficznie cholinergiczny tonus oskrzelowy, obrzęk śluzówki oraz ilość wydzieliny z gruczołów sekrecyjnych, czego nie wykazują SABA [13]. Dlatego też połączenie SAMA z SABA może powodować silniejsze i wydłużone w czasie rozszerzenie oskrzeli u chorych na astmę [14]. Jednakże ciągle istnieją kontrowersje dotyczące skuteczności, bezpieczeństwa kombinacji SABA + SAMA, a także wskazań do niej w astmie u dzieci [15]. Wyżej wymienione leki są dostępne w kraju z inhalatora ciśnieniowego dozującego (pMDI) oraz jako roztwór do nebulizacji. Nebulizacja może być prowadzona kilkoma metodami, przy czym najczęściej stosuje się nebulizatory pneumatyczne pracy ciągłej, nebulizatory pneumatyczne aktywowane wdechem oraz nebulizatory siateczkowe (NS) [16]. Dotychczas nie przeprowadzono badań nad skutecznością kombinacji S z BI inhalowanych z NS u dzieci z astmą.

\section{Cel badania}

Celem zasadniczym badania była ocena porównawcza skuteczności i bezpieczeństwa leczenia bronchodylatacyjnego kombinacji S + BI vs S w monoterapii nebulizowanych przez dzieci chore na astmę w wieku 6-11 lat z cechami klinicznymi i/lub spirometrycznymi zaostrzenia choroby (tj. rozlanej obturacji oskrzeli). Cel dodatkowy stanowiła ocena tolerancji i bezpieczeństwa inhalowanych leków.

\section{Materiał i metody}

Przeprowadzono badanie jednoośrodkowe, randomizowane, interwencyjne, $\mathrm{w}$ grupach równoległych. Zyskało ono zgodę Komisji Bioetycznej przy Uniwersytecie Medycznym w Lublinie ( $\mathrm{nr}$ KE0254/235/2018). Do badania zakwalifikowano dzieci ( $\mathrm{n}=34$, obu płci) w wieku od 6 do 11 lat z zaostrzeniem astmy, u których istniały kliniczne i/lub spirometryczne wskazania do podania leku rozszerzającego oskrzela (salbutamol - grupa S lub salbutamol z bromkiem ipratropium - grupa S + BI) (tab. 1).

Dzieci rekrutowano spośród pacjentów leczonych z powodu astmy w Poradni Pulmonologicznej lub Alergologicznej Uniwersyteckiego Szpitala Dziecięcego (USzD) w Lublinie oraz w Klinice Chorób Płuc i Reumatologii Dziecięcej w Lublinie, gdzie były leczone zgodnie z zaleceniami ekspertów GINA 2018 [17].

Tabela 1. Charakterystyka demograficzna i kliniczna badanych grup dzieci z astma.

\begin{tabular}{|c|c|c|c|}
\hline & Grupa S & Grupa $S+B$ & Razem \\
\hline Liczba dzieci (n) & 18 & 16 & 34 \\
\hline Wiek w latach $(\mathrm{M} \pm \mathrm{SD})$ & $8,5 \pm 2,0$ & $9,1 \pm 2,2$ & $8,8 \pm 2,1$ \\
\hline Płeć (n, m/ż) & $12 / 6$ & $10 / 6$ & $22 / 12$ \\
\hline Astma IgE-zależna [n, (\%)] & $16(88,9)$ & $15(94,7)$ & $32(91,1)$ \\
\hline GKSw lub GKSw + LABA (n) & $10 / 8$ & $9 / 7$ & $19 / 15$ \\
\hline Częstość akcji serca przed podaniem leku (liczba uderzeń na minutę, $\mathrm{M} \pm \mathrm{SD}$ ) & $82,1 \pm 9,2$ & $84,5 \pm 8,9$ & $83,2 \pm 9,1$ \\
\hline Średnia wartość RR w mmHg (M \pm SD) & $108 / 61$ & $109 / 62$ & $108 / 61$ \\
\hline
\end{tabular}

M - średnia arytmetyczna, SD - odchylenie standardowe, RR - ciśnienie tętnicze krwi, GKSw - glikokortykosteroid wziewny, LABA - długo działający $\beta_{2}$-mimetyk wziewny. 


\section{Kryteria włączenia do badania:}

- $\quad$ astma częściowo kontrolowana według GINA 2018 rozpoznana przez lekarza co najmniej 6 miesięcy przed badaniem [17]

- wiek dziecka: 6-17 lat

- umiejętność wykonania poprawnej spirometrii (uprzednio co najmniej raz przeprowadzona poprawnie spirometria w okresie 6-12 miesięcy przed włączeniem do badania)

- umiejętność wykonania poprawnie nebulizacji przez ustnik (uprzednie doświadczenia z nebulizacją)

- zgoda rodziców na udział w badaniu

- spirometryczne cechy obturacji oskrzeli $\mathrm{FEV}_{1} \% \mathrm{FVC}<80 \%$

- bez cech infekcji dróg oddechowych w ostatnich 4 tygodniach przed badaniem.

\section{Kryteria wylączenia $\mathrm{z}$ badania:}

- stosowanie: SABA w ostatnich 6 h, BI w ostatnich 8 h, LABA w ostatniej dobie, teofiliny/aminofiliny w ostatniej dobie, chlorowodorku tiotropium w inhalacji w ostatnich 7 dniach, glikokortykosteroidów podawanych systemowo w ostatnich 30 dniach przed badaniem

- palenie tytoniu bierne i czynne

- $\mathrm{FEV}_{1} \% \mathrm{FVC} \leq 50 \%$.

Badanie przeprowadzono w Pracowni Badań Czynnościowych Układu Oddechowego USzD w Lublinie między listopadem 2018 r. a sierpniem 2019 r. Do badań użyto:

- roztworu salbutamolu 0,2\% (salbutamol sulphate) w postaci preparatu Steri-Neb Salamol ${ }^{\circledR}$, występującego w ampułkach $5 \mathrm{mg} / 2,5 \mathrm{ml}$ firmy IVAX Pharmaceuticals UK, Aston Lane North, Whitehouse Vale Industrial Estate Preston Brook, Runcorn, WA7 3FA Cheshire, GB [18]

- kombinacji salbutamolu $\mathrm{z}$ bromkiem ipratropium w roztworze do nebulizacji; ampułka 2,5 ml zawiera $0,5 \mathrm{mg}$ bromku ipratropium oraz $2,5 \mathrm{mg}$ salbutamolu (preparat Iprixon $\mathrm{Neb}^{\circledR}$ firmy Adamed Sp. z o.o., Polska) [19].

Badane leki podawano przez ustnik z NS typu Intec Twister MESH firmy Intec Medical sp. z o.o., Polska [20]. Dzieci randomizowano do jednej z dwóch grup terapeutycznych:

- grupa $\mathrm{S}$-dzieci leczone $\mathrm{S}(\mathrm{n}=18)$

- grupa SBI - dzieci leczone $\mathrm{S}+\mathrm{BI}(\mathrm{n}=16)$.

Każdy badany otrzymywał jedną ampułkę leku w nebulizacji oraz dodatkowo dawkę 0,15 ml leku ko- nieczną do zapełnienia objętości zalegającej komory nebulizacyjnej tego urządzenia. Badane leki stosowano bez dodatkowego rozcieńczenia, a użyte dawki były zgodne z obecnie obowiązującymi zaleceniami [18, 19, $21,22]$.

Materiałem do analizy statystycznej były wyniki badania spirometrycznego przeprowadzonego w czasie: 0 min i 15 min po podaniu leku/leków rozszerzających oskrzela w każdej grupie terapeutycznej. Ocenę spirometryczną bronchodylatacyjnej odpowiedzi oskrzeli przeprowadzono według aktualnych wytycznych ATS/ERS [4]. Do badań użyto spirometru. Analizowano następujące parametry spirometryczne:

- FVC - nasilona pojemność życiowa płuc

- $\mathrm{FEV}_{1}$ - nasilona objętość wydechowa pierwszosekundowa

- PEF - szczytowy przepływ wydechowy

- $\mathrm{FEF}_{25-75}$ - nasilony przepływ śródwydechowy między $25 \%$ a $75 \%$ FVC.

Zmienną badaną pierwszorzędową była zmiana $\mathrm{w}^{\mathrm{FEV}} \mathrm{V}_{1}$ po zastosowaniu leku vs $\mathrm{FEV}_{1}$ przed lekiem $\left(\triangle \mathrm{FEV}_{1}\right)$, a zmienną drugorzędową - analogiczne zmiany $\mathrm{w}$ wartościach PEF $\mathrm{i} \mathrm{FEF}_{25-75}(\triangle \mathrm{PEF}$ i $\left.\Delta \mathrm{FEF}_{25-75}\right)$ [23]. Następnie dokonano analizy porównawczej stopnia zmian w badanych wskaźnikach spirometrycznych między grupą S a S + BI. Oceniono też liczbę i odsetek dzieci z $\Delta \mathrm{FEV}_{1} \geq 15 \%$. Ocena bezpieczeństwa obu leków opierała się na obserwacji klinicznej dzieci oraz pomiarze co 15 min w okresie 1. godziny po podaniu leku:

- wartości ciśnienia tętniczego

- akcji serca.

Dane zostały opracowane statystycznie za pomocą aktualnego programu Statistica.

\section{Wyniki}

W tabeli 2 ukazano wyniki badań spirometrycznych u dzieci przed podaniem S + BI lub S i po nim.

Nie stwierdzono różnic istotnych statystycznie w zachowaniu się badanych parametrów spirometrycznych między grupą $\mathrm{S}$ a grupą $\mathrm{S}+\mathrm{BI}$.

W tabeli 3 przedstawiono działania niepożądane zaobserwowane $\mathrm{u}$ badanych dzieci $\mathrm{w}$ trakcie 1. godziny po podaniu leku. Wykazano nieco częstsze objawy w grupie S niż w S + BI.

Nie zaobserwowano istotnej statystycznie zależności między grupą badaną a występowaniem poszczególnych działań niepożądanych. 
Tabela 2. Wartości wyjściowe badanych parametrów spirometrycznych oraz odpowiedź oskrzeli na badane leki $w$ analizowanych grupach dzieci.

\begin{tabular}{|c|c|c|c|c|}
\hline Parametry spirometryczne & $\begin{array}{l}\text { Grupa } S \\
M \pm \mathrm{SD}_{\text {min-max }}\end{array}$ & $\begin{array}{l}\text { Grupa } S+B \mid \\
M \pm S D_{\text {min-max }}\end{array}$ & Wartość p & Tes \\
\hline $\begin{array}{l}\text { Wyjściowe } \\
\mathrm{FEV}_{1} \% \text { w.n. }\end{array}$ & $\begin{array}{l}71,1 \pm 12,3 \\
37,0-79,9\end{array}$ & $\begin{array}{l}69,8 \pm 10,9 \\
48,3-78,5\end{array}$ & $p>0,05$ & t-Studenta \\
\hline $\begin{array}{l}\text { Wyjściowe } \\
\mathrm{FEF}_{25-75} \% \text { w.n. }\end{array}$ & $\begin{array}{l}48,5 \pm 9,3 \\
33,0-61,1\end{array}$ & $\begin{array}{l}52,9 \pm 12,6 \\
28,9-77,7\end{array}$ & $p>0,05$ & t-Studenta \\
\hline $\begin{array}{l}\text { Wyjściowe } \\
\text { FVC\% w.n. }\end{array}$ & $\begin{array}{l}88,5 \pm 18,5 \\
39,0-110,0\end{array}$ & $\begin{array}{l}91,3 \pm 17,1 \\
44,0-103,0\end{array}$ & $p>0,05$ & t-Studenta \\
\hline$\Delta \mathrm{FEV}_{1}$ & $\begin{array}{l}15,5 \pm 4,8 \\
2,0-47,0\end{array}$ & $\begin{array}{l}17,8 \pm 5,6 \\
3,0-48,2\end{array}$ & $p>0,05$ & t-Studenta \\
\hline$\triangle \mathrm{PEF}$ & $\begin{array}{l}56,0 \pm 13,9 \\
37,0-81,0\end{array}$ & $\begin{array}{l}53,4 \pm 12,7 \\
35,5-80,1\end{array}$ & $p>0,05$ & t-Studenta \\
\hline$\Delta \mathrm{FEF}_{25-75}$ & $\begin{array}{l}34,9 \pm 25,7 \\
5,0-100,0\end{array}$ & $\begin{array}{l}38,3 \pm 26,1 \\
10,0-96,0\end{array}$ & $p>0,05$ & t-Studenta \\
\hline$\Delta \mathrm{FEV}_{1} \geq 15 \%(\mathrm{n}, \%)$ & $11(61)$ & $13(82)$ & $p>0,05$ & chi-kwadrat \\
\hline
\end{tabular}

M-średnia arytmetyczna, SD - odchylenie standardowe.

Tabela 3. Działania niepożądane zaobserwowane/zgłaszane u badanych dzieci w trakcie 1. godziny po podaniu leku.

\begin{tabular}{|c|c|c|c|c|c|}
\hline \multirow[t]{2}{*}{ Działanie niepożądane } & \multicolumn{2}{|c|}{$\begin{array}{l}\text { Grupa S } \\
(n=18)\end{array}$} & \multicolumn{2}{|c|}{$\begin{array}{l}\text { Grupa } S+B I \\
\quad(n=16)\end{array}$} & \multirow{2}{*}{ Wynik testu statystycznego } \\
\hline & $\mathrm{n}$ & $\%$ & $n$ & $\%$ & \\
\hline Drżenia mięśni & 2 & 11,1 & 0 & 0 & $\begin{array}{l}\lambda^{2}(1)=2,25 \\
p=0,49\end{array}$ \\
\hline Bóle głowy & 1 & 5,6 & 0 & 0 & $\begin{array}{l}\lambda^{2}(1)=0,92 \\
p=1\end{array}$ \\
\hline Przyspieszenie akcji serca* & 2 & 11,1 & 1 & 6,3 & $\begin{array}{l}\lambda^{2}(1)=0,25 \\
p=1\end{array}$ \\
\hline Podwyższone ciśnienie tętnicze krwi* & 2 & 11,1 & 0 & 0 & $\begin{array}{l}\lambda^{2}(1)=2,25 \\
p=0,49\end{array}$ \\
\hline Obniżenie ciśnienia rozkurczowego* & 0 & 0 & 1 & 6,3 & $\begin{array}{l}\lambda^{2}(1)=1,16 \\
p=0,47\end{array}$ \\
\hline Podrażnienie błony śluzowej jamy ustnej i gardła & 2 & 11,1 & 2 & 12,5 & $\begin{array}{l}\lambda^{2}(1)=0,02 \\
p=1\end{array}$ \\
\hline Nudności & 0 & 0 & 1 & 6,3 & $\begin{array}{l}\lambda^{2}(1)=1,16 \\
p=0,47\end{array}$ \\
\hline Razem & 9 & 50 & 5 & 31,3 & $\begin{array}{l}\lambda^{2}(1)=1,23 \\
p=0,32\end{array}$ \\
\hline
\end{tabular}

* Ocena według [24, 25].

\section{Dyskusja}

Dostępne publikacje dotyczące wdrożenia kombinacji SABA i SAMA w zaostrzeniu astmy u dzieci prowadzą do kilku wniosków [26-32]. Po pierwsze, terapia inhalacyjna $\mathrm{S}+\mathrm{BI}$ stosowanych jednocześnie jest skutecznym i bezpiecznym postępowaniem w leczeniu zaostrzeń astmy u dzieci, w tym także astmy wczesnodziecięcej, zarówno w warunkach ambulatoryjnych, jak i na szpitalnym oddziale ratunkowym (SOR). Po drugie, kombinacja tych leków inhalacyjnych jest szczególnie skuteczna w umiarkowanym/ ciężkim zaostrzeniu astmy, niezależnie od wieku dzieci. Jednoczesna terapia $\mathrm{S}+\mathrm{BI}$ zmniejsza istotnie 
ryzyko hospitalizacji w porównaniu $\mathrm{z}$ lekami stosowanymi pojedynczo (o $27 \%$ vs tylko SABA i o $74 \%$ vs tylko SAMA). Po trzecie, kombinacja S + BI w inhalacji jest dobrze tolerowana przez dzieci w różnym wieku, zmniejsza ryzyko wystąpienia nudności i drżeń mięśniowych w porównaniu z lekami stosowanymi pojedynczo. W większości dostępnych publikacji kombinację SABA z SAMA podawano z pMDI, rzadziej z nebulizatorów pneumatycznych pracy ciągłej. Kombinacją o podobnej skuteczności do S + BI jest połączenie F z BI z pMDI lub w nebulizacji [33, 34]. Dotychczas opublikowano jedynie kilka badań z kombinacją SABA + SAMA z NS, jednakże wszystkie dotyczyły dorosłych [35-39]. Są też dostępne pojedyncze badania z $\mathrm{S}$ inhalowanym z różnych typów NS u dzieci i dorosłych $z$ astmą $[40,41]$.

Przedstawione badanie to pierwsze kliniczne badanie u dzieci leczonych kombinacją $\mathrm{S}+\mathrm{BI}$ z użyciem NS. NS są nowoczesnymi urządzeniami inhalacyjnymi wykorzystywanymi do nebulizacji roztworów i zawiesin różnych leków. Jednym z bardziej popularnych w kraju jest urządzenie Intec Twister Mesh NE-105. To NS aktywny, w którym zasilany prądem kryształ piezoelektryczny generuje drgania plastikowej membrany siateczkowej będącej w kontakcie z roztworem leku [20]. Cechuje go praca ciągła (ze stałą produkcją aerozolu), niezależna od wdechu chorego.

Wyniki przedstawianego badania potwierdzają efektywność i bezpieczeństwo $\mathrm{S}+\mathrm{BI}$ w nebulizacji w zaostrzeniach astmy u dzieci, w tym u dzieci w wieku 6-11 lat. Jednakże jest to pierwsze doniesienie $\mathrm{w}$ tej grupie wiekowej chorych na astmę ocenianych spirometrycznie 15 min po podaniu kombinacji $\mathrm{S}+\mathrm{BI}$ nebulizowanej z NS. Nie wykazano w nim różnicy w spirometrycznej ocenie efektywności bronchodylatacyjnej inhalowanych leków w zależności od użytego preparatu po 15 min od podania leku.

Podobne dane płyną z innych badań, gdzie SABA + SAMA inhalowano z pMDI lub z nebulizatorów pneumatycznych [42]. Większy efekt bronchodylatacyjny kombinacji SABA + SAMA vs SABA obserwuje się dopiero po ok. $120 \mathrm{~min}$ od inhalacji [43]. Tłumaczy się to innym mechanizmem działania SAMA vs SABA oraz efektem częściowej synergii obu leków [44, 45]. Być może badanie spirometryczne przeprowadzone po $120 \mathrm{~min}$ pokazałoby lepszy efekt bronchodylatacyjny $\mathrm{S}+\mathrm{BI}$ vs $\mathrm{S}$, co jednak nie było przedmiotem badania. Zaobserwowano nieco lepszą tolerancję S + BI vs S, co może wynikać z mniejszej dawki salbutamolu w tym preparacie $\mathrm{S}+\mathrm{BI}$ (w jednej ampułce kombinacji $\mathrm{S}+\mathrm{BI}$ jest 2,5 $\mathrm{mg} \mathrm{S}$, a w ampułce $\mathrm{S}-5 \mathrm{mg})$.

\section{Wnioski}

1. Kombinacja salbutamolu $\mathrm{z}$ bromkiem ipratropium wywiera podobny efekt bronchodylatacyjny jak sam salbutamol $\mathrm{w}$ nebulizacji $\mathrm{z}$ nebulizatora siateczkowego po $15 \mathrm{~min}$ od podania leku u dzieci z cechami spirometrycznymi obturacji oskrzeli.

2. Tolerancja obu badanych metod leczenia oceniana w czasie 1 . godziny po nebulizacji jest podobna.

\section{Piśmiennictwo}

1. Global Strategy for Asthma Management and Prevention, Global Initiative for Asthma (GINA) Update 2020. https:// ginasthma.org/wp-content/uploads/2020/04/GINA-2020-full-report_final__wms.pdf (Access: 25.05.2019).

2. Ducharme FM, Sharon DD, Radhakrishnan D et al. Diagnosis and management of asthma in preschoolers: a Canadian Thoracic Society and Canadian Paediatric Society position paper. Can Respir J. 2015; 22: 135-43.

3. Doniec Z, Mastalerz-Migas A, Bręborowicz A et al. Rekomendacje postępowania $w$ astmie wczesnodziecięcej dla lekarzy Podstawowej Opieki Zdrowotnej - KOMPAS POZ. Fam Med Prim Care Review. 2016; 8: 81-92.

4. Graham BL, Steenbruggen I, Miller MR et al. Standardization of Spirometry 2019 Update An Official American Thoracic Society and European Respiratory Society Technical Statement. Am J Respir Crit Care Med. 2019; 200: e70-e88.

5. Hochhaus G, Möllmann H. Pharmacokinetic/pharmacodynamic characteristics of the beta-2-agonists terbutaline, salbutamol and fenoterol. Int J Clin Pharmacol Ther Toxicol. 1992; 30: 342-62.

6. Lawford P, Dowd DE, Palmer KN. A comparison of the duration of action of fenoterol and salbutamol in asthma. Curr Med Res Opin. 1981; 7: 349-51.

7. Scalabrin DM, Solé D, Naspitz CK et al. Efficacy and side effects of beta 2-agonists by inhaled route in acute asthma in children: comparison of salbutamol, terbutaline, and fenoterol. J Asthma. 1996; 33: 407-15.

8. Bremner P, Burgess C, Beasley $R$ et al. Nebulized fenoterol causes greater cardiovascular and hypokalaemic effects than equivalent bronchodilator doses of salbutamol in asthmatics. Respir Med. 1992; 86: 419-23.

9. Bremner P, Siebers R, Crane J et al. Partial vs full beta-receptor agonism. A clinical study of inhaled albuterol and fenoterol. Chest. 1996; 109: 957-62.

10. Bremner P, Burgess CD, Crane J et al. Cardiovascular effects of fenoterol under conditions of hypoxaemia. Thorax. 1992; 47: 814-7.

11. SIGN 158. British Guideline on the Management of Asthma. A national clinical guideline. Revised edition July 2019. 
www.brit-thoracic.org.uk/Portals/0/Guidelines/AsthmaGuidelines (Access: 3.10.2019).

12. Pollock M, Sinha I, Hartling $L$ et al. Inhaled short-acting bronchodilators for managing emergency childhood asthma: an overview of reviews. Allergy. 2017; 72: 183-200.

13. Qureshi F, Zaritsky A, Lakkis H. Efficacy of nebulized ipratropium in severely asthmatic children. Ann Emerg Med. 1997; 29: 205-11.

14. Griffiths B, Ducharme FM. Combined inhaled anticholinergics and short-acting beta2-agonists for initial treatment of acute asthma in children. Cochrane Database Syst Rev. 2013; (8): CD000060. http://doi.org/10.1002/14651858.CD000060.pub2.

15. Rehder KJ. Adjunct therapies for refractory status asthmaticus in children. Respir Care. 2017; 62: 849-65.

16. Pirożyński M, Florkiewicz E, Sosnowski T. Podstawy nebulizacji - rodzaje inhalatorów. In: Pirożyński M (ed). ABC nebulizacji ze szczególnym uwzględnieniem dawkowania. Via Medica, Gdańsk 2015: 27-42

17. Global Strategy for Asthma Management and Prevention, Global Initiative for Asthma (GINA)Update 2018. https:// ginasthma.org/wp-content/uploads/2018/04/wms-GINA2018-report-tracked_v1.3.pdf (Access: 6.06.2018).

18. www.teva.pl/itemserver/produkt/pdf_2012/Steri_Neb_Salamol_NEB_PIL_2011_12_21.pdf(Access: 6.06.2018).

19. https://www.mp.pl/pacjent/leki/lek/92844,Iprixon-Neb-roztwor-do-nebulizacji (Access: 6.06.2018).

20. Intec Twister Mesh Membrane Inhaler. Operation Manual 2016 - in Polish. https://docplayer.pl/19474476Inhalator-mesh-instrukcja-obslugi-intec-ne-105.html (Access: 30.05.2020).

21. Pirożyński M, Florkiewicz E, Bodasińki J et al. Calculation of the delivered dose in patients undergoing nebulized asthma therapy. Respir Drug Deliv Europe. 2017; 2: 269-72.

22. Bodasiński J, Emeryk A, Florkiewicz E et al. Nebulizacja: czym, jak, dla kogo, kiedy? Polski Konsensus Nebulizacyjny. Terapia. 2013; nr specjalny: 3-10.

23. Boros P, Franczuk M, Wesolowski S. Zasady interpretacji wyników badania spirometrycznego. Zalecenia Polskiego Towarzystwa Chorób Pluc (dawniej Polskie Towarzystwo Ftyzjopneumonologiczne) dotyczace wykonywania badań spirometrycznych. Pneum Alergol Pol. 2006; 74(suppl 1): 1-23.

24. Fleming $S$, Thompson $M$, Stevens $R$ et al. Normal ranges of heart rate and respiratory rate in children from birth to 18 years: a systematic review of observational studies. Lancet. 2011; 377(9770): 1011-8.

25. De Caen AR, Berg MD, Chameides L et al. 2015 American Heart Association Guidelines Update for Cardiopulmonary Resuscitation and Emergency Cardiovascular Care. Circulation. 2015; 132: S526-42.

26. Anthracopoulos MB, Karatza AA, Davlouros PA et al. Effects of two nebulization regimens on heart rate variability during acute asthma exacerbations in children. J Asthma. 2005; 42: 273-9.

27. Castro-Rodriguez JA, Rodrigo GJ, Rodríguez-Martínez CE. Principal findings of systematic reviews of acute asthma treatment in childhood. J Asthma. 2015; 52: 1038-45.

28. Coskun S, Yuksel H, Tikiz $H$ et al. Standard dose of inhaled albuterol significantly increases QT dispersion compared to low dose of albuterol plus ipratropium bromide therapy in moderate to severe acute asthma attacks in children. Pediatr Int. 2001; 43: 631-6.

29. Craven D, Kercsmar CM, Myers TR et al. Ipratropium bromide plus nebulized albuterol for the treatment of hospitalized children with acute asthma. J Pediatr. 2001; 138: 51-8.

30. Iramain R, López-Herce J, Coronel J et al. Inhaled salbutamol plus ipratropium in moderate and severe asthma crises in children. J Asthma. 2011; 48: 298-303.

31. Memon BN, Parkash A, Ahmed Khan KM et al. Response to nebulized salbutamol versus combination with ipratropium bromide in children with acute severe asthma. J Pak Med Assoc. 2016; 66: 243-6.

32. Vézina K, Chauhan BF, Ducharme FM. Inhaled anticholinergics and short-acting beta(2)-agonists versus short-acting beta2-agonists alone for children with acute asthma in hospital. Cochrane Database Syst Rev. 2014; (7): CD010283.

33. Louw SJ, Goldin JG, Isaacs S. Relative efficacy of nebulised ipratropium bromide and fenoterol in acute severe asthma. S Afr Med J. 1990; 77(1): 24-6.

34. Watson WT, Becker AB, Simons FE. Comparison of ipratropium solution, fenoterol solution, and their combination administered by nebulizer and face mask to children with acute asthma. J Allergy Clin Immunol. 1988; 82(6): 1012-8.

35. Galindo-Filho VC, Alcoforado L, Rattes $C$ et al. A mesh nebulizer is more effective than jet nebulizer to nebulize bronchodilators during non-invasive ventilation of subjects with COPD: A randomized controlled trial with radiolabeled aerosols. Respir Med. 2019; 153: 60-7.

36. Yang SH, Yang TM, Lin HL et al. Size distribution of salbutamol/ipratropium aerosols produced by different nebulizers in the absence and presence of heat and humidification. Pulm Pharmacol Ther. 2018; 48: 22-7.

37. Loborec SM, Johnson SE, Keating EA. Financial effect of converting ipratropium-albuterol therapy from inhalers to nebulizer treatments at an academic health system. Am J Health Syst Pharm. 2016; 73(3): 121-5.

38. Lee YH, Kwon GY, Park DY et al. Efficiency of a New Mesh-Type Nebulizer (NE-SM1 NEPLUS) for Intrapulmonary Delivery of Ipratropium Bromide in Surgical Patients. Basic Clin Pharmacol Toxicol. 2016; 118(4): 313-9.

39. Golden LR, DeSimone HA, Yeroshalmi F et al. Severe intraoperative bronchospasm treated with a vibrating-mesh nebulizer. Anesth Prog. 2012; 59(3): 123-6. 
40. Murayama N, Murayama K. Comparison of the clinical efficacy of salbutamol with jet and mesh nebulizers in asthmatic children. Pulm Med. 2018; 1648652.

41. Kurosaka F, Nishio H. Comparison of the bronchodilative effects of salbutamol delivered via three mesh nebulizers in children with bronchial asthma. Allergology Int. 2009; 58: 529-35.

42. Kirkland $S W$, Vandenberghe Ch, Voaklander B et al. Combined inhaled beta-agonist and anticholinergic agents for emergency management in adults with asthma. Cochrane Database Syst Rev. 2017; 2017(1): CD001284.

43. Jenkins CR, Chow CM, Fisher BL et al. Ipratropium bromide and fenoterol by aerosolized solution. Br J Clin Pharmac. 1982; 14: 113-5.

44. Petrie GR, Palmer KN. Comparison of aerosol ipratropium bromide and salbutamol in chronic bronchitis and asthma. Br Med J. 1975; 5955: 430-2.

45. Thiessen B, Pedersen OF. Maximal expiratory flows and forced vital capacity in normal, asthmatic and bronchitic subjects after salbutamol and ipratropium bromide respiration. Respiration. 1982; 43(4): 304-16.
ORCID

A. Emeryk - ID - http://orcid.org/0000-0003-1853-8696

I. Czerwińska-Pawluk - ID - http://orcid.org/0000-0001-7412-4173

E. Markut-Miotła - ID - http://orcid.org/0000-0002-3657-1134

K. Janeczek - ID - http://orcid.org/0000-0002-8163-873X

Wkład autorów/Authors' contributions: A. Emeryk: koncepcja pracy, przygotowanie maszynopisu; I. Czerwińska-Pawluk: przeprowadzenie badań spirometrycznych; E. Markut-Miotła: koncepcja pracy, przygotowanie maszynopisu, zebranie piśmiennictwa; K. Janeczek: statystyka, przygotowanie maszynopisu.

Konflikt interesów/Conflict of interests:

Nie występuje.

Finansowanie/Financial support:

Nie występuje.

Etyka/Ethics:

Treści przedstawione w artykule są zgodne z zasadami Deklaracji Helsińskiej, dyrektywami

EU oraz ujednoliconymi wymaganiami dla czasopism biomedycznych.

Copyright: (C) Medical Education sp. z 0.0. This is an Open Access article distributed under the terms of the Attribution-NonCommercial 4.0 International (CC BY-NC 4.0). License (https://creativecommons.org/licenses/by-nc/4.0/), allowing third parties to copy and redistribute the material in any medium or format and to remix, transform, and build upon the material, provided the original work is properly cited and states its license.

Adres do korespondencji

prof. dr hab. n. med. Andrzej Emeryk

Klinika Chorób Płuc i Reumatologii Dziecięcej,

Uniwersytet Medyczny w Lublinie,

Uniwersytecki Szpital Dziecięcy w Lublinie

20-093 Lublin, ul. A. Gębali 6

tel.: 81 718-54-77

e-mail: emerykandrzej@gmail.com 